\title{
BMJ Open Factors associated with incomplete immunisation in children aged 12-23 months at subnational level, Nigeria: a cross-sectional study
}

\author{
Paul Eze (10 , ${ }^{1}$ Ujunwa Justina Agu, ${ }^{2}$ Chioma Lynda Aniebo, ${ }^{2}$ Sergius Alex Agu, ${ }^{3}$ \\ Lucky Osaheni Lawani, ${ }^{4}$ Yubraj Acharya ${ }^{1}$
}

To cite: Eze P, Agu UJ, Aniebo CL, et al. Factors associated with incomplete immunisation in children aged 12-23 months at subnational level, Nigeria: a crosssectional study. BMJ Open 2021;11:e047445. doi:10.1136/ bmjopen-2020-047445

- Prepublication history and additional supplemental material for this paper are available online. To view these files, please visit the journal online. To view these files, please visit the journal online (http://dx.doi. org/10.1136/bmjopen-2020047445).

Received 28 November 2020 Accepted 26 May 2021

Check for updates

(C) Author(s) (or their employer(s)) 2021. Re-use permitted under CC BY-NC. No commercial re-use. See rights and permissions. Published by BMJ.

${ }^{1}$ Department of Health Policy and Administration, Penn State University, University Park, Pennsylvania, USA

${ }^{2}$ Department of Paediatrics, Enugu State University Teaching Hospital, Parklane, Enugu, Nigeria

${ }^{3}$ Department of Paediatrics, University of Nigeria Teaching Hospital, Enugu, Nigeria

${ }^{4}$ Institute of Health Policy, Management \& Evaluation, University of Toronto, Toronto, Ontario, Canada

Correspondence to

Paul Eze; peze@psu.edu

\section{ABSTRACT}

Objectives National immunisation coverage rate masks subnational immunisation coverage gaps at the state and local district levels. The objective of the current study was to determine the sociodemographic factors associated with incomplete immunisation in children at a sub-national level.

Design Cross-sectional study using the WHO sampling method (2018 Reference Manual).

Setting Fifty randomly selected clusters (wards) in four districts (two urban and two rural) in Enugu state, Nigeria.

Participants 1254 mothers of children aged 12-23 months in July 2020.

Primary and secondary outcome measures Fully immunised children and not fully immunised children. Results Full immunisation coverage (FIC) rate in Enugu state was $78.9 \%$ (95\% Cl $76.5 \%$ to $81.1 \%$ ). However, stark difference exists in FIC rate in urban versus rural districts. Only $55.5 \%$ of children in rural communities are fully immunised compared with $94.5 \%$ in urban communities. Significant factors associated with incomplete immunisation are: children of single mothers $(\mathrm{aOR}=5.74$, $95 \% \mathrm{Cl} 1.45$ to 22.76 ), children delivered without skilled birth attendant present (aOR=1.93, 95\% $\mathrm{Cl} 1.24$ to 2.99), children of mothers who did not receive postnatal care ( $\mathrm{aOR}=6.53,95 \% \mathrm{Cl} 4.17$ to 10.22 ), children of mothers with poor knowledge of routine immunisation $(\mathrm{aOR}=1.76$, $95 \% \mathrm{Cl} 1.09$ to 2.87$)$, dwelling in rural district $(\mathrm{aOR}=7.49$, $95 \% \mathrm{Cl} 4.84$ to 11.59 ), low-income families ( $\mathrm{aOR}=1.56$, $95 \% \mathrm{Cl} 1.17$ to 2.81 ) and living further than $30 \mathrm{~min}$ from the nearest vaccination facility $(\mathrm{aOR}=2.15,95 \% \mathrm{Cl} 1.31$ to 3.52).

Conclusions Although the proportion of fully immunised children in Enugu state is low, it is significantly lower in rural districts. Study findings suggest the need for innovative solutions to improve geographical accessibility and reinforce the importance of reporting vaccination coverage at local district level to identify districts for more targeted interventions.

\section{INTRODUCTION}

Immunisation, defined as the process that makes a person immune or resistant to an infectious disease, typically by the administration of a vaccine, is one of the most effective
Strengths and limitations of this study

- The estimates presented in the study for the subnational level are potentially more accurate than previous estimates.

- We adhered to the guidelines in WHO Vaccination Coverage Cluster Surveys Reference Manual 2019, thus enabling greater comparability with future studies using the same method.

- Due to the observational cross-sectional design, we cannot establish a causal relationship between these factors and vaccination.

- This study considerably relied on maternal recall which can lead to overestimation or underestimation of immunisation coverage estimates.

- We were unable to access pockets of historically healthcare-marginalised population in one of the settlements due to security concerns.

interventions in contemporary public health practice. $^{1}{ }^{2}$ Several cost-benefits analyses have consistently placed immunisation as one of the most cost-effective health interventions with huge direct and societal benefits. ${ }^{3-8}$ Immunisation saves about 2-3 million lives every year, ${ }^{12}$ and has successfully led to the elimination of a number of vaccinepreventable diseases in some high-income countries, including polio, diphtheria and pertussis. ${ }^{3} 9$ Indeed, childhood immunisation has had a remarkable impact on child morbidity and mortality worldwide with immense positive multiplier effects on the larger communities. ${ }^{359}$

Nigeria is one of the 10 countries (Angola, Brazil, the Democratic Republic of the Congo, Ethiopia, India, Indonesia, Mexico, Nigeria, Pakistan and the Philippines) that account for over $60 \%$ of the children who did not get DPT3 in 2019. ${ }^{1}$ DTP3 coverage is an indicator of how well countries are providing routine immunisation (RI) services. ${ }^{2}$ In 2017, about 
$20 \%$ of the world's infants with incomplete DPT immunisation lived in Nigeria. ${ }^{10}$ Three million of the estimated 8.9 million infants in the WHO African Region who did not receive any measles containing vaccine in 2015 live in Nigeria. ${ }^{11}$ Hence, Nigeria accounts for nearly $40 \%$ of the 28279 confirmed measles cases reported from the WHO African Region in 2016. ${ }^{12}$

The Expanded Programme on Immunization in Nigeria, created in 1979, had a significant impact during the first few years with immunisation coverage peaking at $81.5 \%$ in $1990 .{ }^{13-15}$ Immunisation coverage plummeted to $12.3 \%$ in $2003,{ }^{15}$ due to a myriad of factors including low government commitment to Expanded Programme on Immunization (EPI) policy, over-centralisation in the administration of EPI at the federal level, collapse of the primary healthcare service on which EPI services were delivered, and vaccination refusal mostly due to religious beliefs in the northern part of the country. ${ }^{15}$ Several strategies were deployed in subsequent years to address the low immunisation coverage, including RI strengthening, supplemental immunisation activities, global positioning system tracker and several community-level interventions. ${ }^{16}$ Despite these efforts, preliminary results of the 2019 National Nutrition and Health Survey suggests a national DTP3 coverage of $67 \% .{ }^{17}$ However, even the low national immunisation coverage rates mask subnational immunisation coverage gaps at the state and local district levels. ${ }^{18}$ For example, immunisation coverage ranged from $5 \%$ to $48 \%$ across states in northern Nigeria in the 2018 National Demographic and Health Survey (DHS). ${ }^{19}$

The Immunization Agenda 2030 (IA2030) is a global strategy led by the WHO to ensure every child is protected by full immunisation, regardless of location, age, socioeconomic status or gender-related barriers by $2030 .{ }^{20}$ Despite overall improvements in immunisation coverage at the national level, ${ }^{21}$ geographic variations in the immunisation coverage persists at most subnational and district levels. ${ }^{18}$ Achieving geographical parity, however, depends on capturing and understanding local patterns of coverage required to provide optimal, child-focused vaccine delivery services. ${ }^{18}$ Also, while nationally representative surveys such as the DHS and Multiple Indicator Cluster Survey have a standardised data collection procedures across countries that is also consistent over time, ${ }^{22}$ presenting immunisation coverage at national levels fails to capture the all-important local patterns of coverage required to properly fine-tune vaccine delivery services. Furthermore, relying on subnational administrative data for assessing immunisation system performance and tracking progress is often fraught with limitations such as missing data and poor data quality. ${ }^{1823}$

This study seeks to identify the factors associated with incomplete immunisation at the subnational level using Enugu state as point of focus. Enugu state has a high number of unimmunised children, ${ }^{24}$ and has the lowest proportion of children with complete immunisation in the southeast region. ${ }^{25}$ Hence, employing the WHO multi-stage sampling methods for community survey, ${ }^{26}$ this study aims to identify the sociodemographic factors associated with incomplete immunisation in children aged 12-23 months at a subnational and local level. Our findings could help tailor strategies and operational plans to address immunisation gaps and reach children in every district with life-saving vaccines.

\section{METHODS}

This was a community-based cross-sectional survey of mothers of children 12-23 months old residing in Enugu state in July 2020. The study considered all children 12-23 months old eligible for sampling, and used the Strengthening the Reporting of Observational Studies in Epidemiology guidelines to ensure appropriate reporting of its study's design, conduct and findings. ${ }^{27}$

\section{Study setting}

Nigeria is the most populous country in Africa and the sixth most populous in the world. ${ }^{28}$ She is located in Western Africa and is divided into six geopolitical regions: northeast, northwest, northcentral, southsouth, southeast and southwest. She has 36 states-the second administrative division, and a federal capital territory in Abuja. Each state is further divided into smaller administrative units called local government areas (LGAs) and each LGA is further divided into wards.

Enugu state is one of the 36 states in Nigeria (figure 1) and one of the five states that make up the southeast geopolitical region in the country. Enugu state is further divided into 17 LGAs, four of which are predominantly urban (Enugu East, Enugu North, Enugu South and Nsukka) and the rest are predominantly rural. Enugu state's 2020 projected population is 4769 916, with most of the population living in urban centres in Enugu and Nsukka. ${ }^{29} 30$

\section{Sample size}

Using steps described in the WHO Vaccination Coverage Cluster Surveys Reference Manual 2019, ${ }^{26}$ we determined the sample size using immunisation coverage of $36.0 \%$ obtained for Enugu state in the most recent 2018 Nigeria DHS ${ }^{25}$ significance level of $5.0 \%$, precision of $5.0 \%$, design effect of $2.5^{31}$ and an inflation of $15 \%$ (to account for non-response). The calculated minimum sample size was 1183 which we increased to 1250 to boost the power of the study.

\section{Sampling procedure}

We used a three-stage sampling technique. In the first stage, we used a simple random sampling technique by balloting to select four LGAs: two each from the urban and rural areas of the state. In the second stage, we randomly selected (by balloting) a total of 50 clusters based on probability-proportional-to-population: 15 clusters from Enugu East LGA, 15 clusters from Enugu North LGA and 10 clusters each from Ezeagu LGA and Udenu LGA. In the third stage, we selected 25 households in 


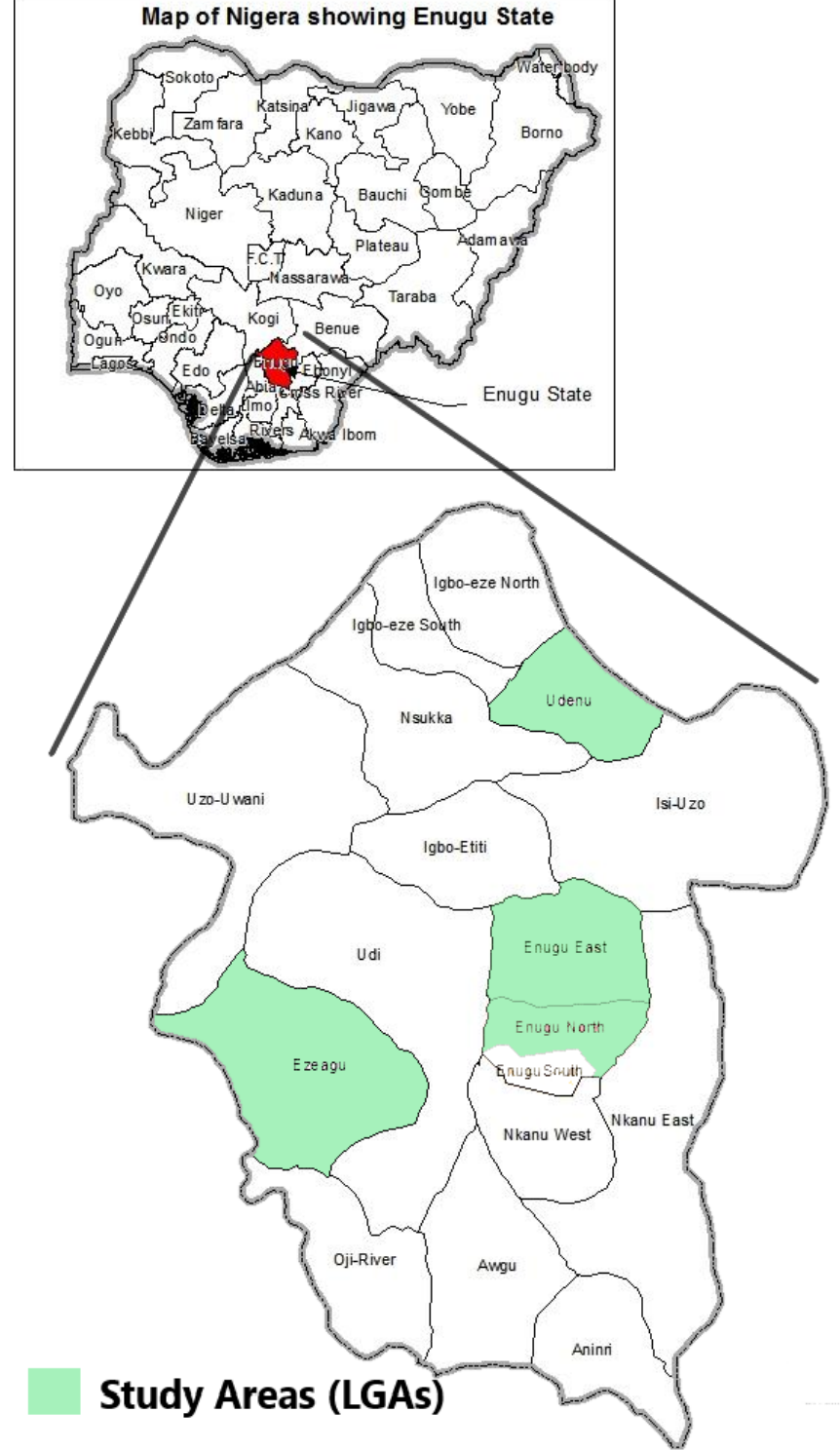

Figure 1 Map of Nigeria above showing Enugu state and map of Enugu state showing the study area (four local government areas (LGAs)). Adapted from image culled from Ugoyibo et $a l^{61}$.

each of the 50 clusters (ward). In each cluster, we selected the first household randomly and subsequent households contiguously in the right direction until we achieved the required number of households for that cluster. From each selected household, we selected one eligible child. If a selected household had more than one eligible child, we selected the youngest child older than 12 months. If a selected household had no eligible child, we visited the next contiguous household, and selected one eligible child.

\section{Data collection}

A team of 14 trained community health workers collected the data using structured pretested intervieweradministered questionnaires. We constructed the questionnaire from a review of the available literature on immunisation surveys in similar contexts, ${ }^{32-34}$ and tested it for acceptability and logical structure in a sample of 20 mothers before the study. Prior to the survey, we trained the team on the study's objectives, interpreting and extracting data from health cards/vaccination certificates, sampling techniques, walking distance estimation using Google Maps mobile app, ethical issues including the process of taking informed verbal consent and administration of the questionnaire. We administered the questionnaire in Igbo (the local language) except for a few non-Igbo speakers whom we administered the questionnaire in English. The research team directed the questions to the mothers and recorded only their responses.

Data we collected include sociodemographic characteristics of mothers and children including maternal healthcare (MHC) utilisation (ante-natal care (ANC), skilled birth attendant (SBA) present at birth and post-natal care (PNC)), knowledge of mothers regarding RI, immunisation status of children and reasons for any non-vaccination. If the immunisation card was available, we recorded immunisation information of each inoculation the child received. If a child had never received an immunisation card or the mother was unable to present the immunisation card to the interviewer, the immunisation data/information for the child was based on the mother's report.

We used Google Map mobile app on smartphones to estimate the walking distance from each study participant's house to the nearest vaccination centre in all but four clusters (in Ezeagu LGA). In these four clusters, we first identified the nearest routine childhood vaccination point in each cluster and then estimated the walking distance from this nearest vaccination facility to each household included in the study. To evaluate mothers' knowledge of RI and vaccinepreventable diseases, the interviewers asked questions on the correct purpose of immunisation, different vaccinepreventable diseases, the correct age for receiving the vaccines and the total number of visits required to complete the recommended vaccination for the child. We evaluated the responses as per the National Primary Healthcare Development Agency RI schedule. ${ }^{35}$ We coded correct responses as 2 points, incorrect responses 1 point, 'I do not know' 0 (zero) point.

\section{Outcome variable}

We categorised children as fully immunised, partially immunised or unimmunised (zero-dose) based on the types and doses of antigens received. We defined a 'fully immunised child' as a child who had received one dose of BCG, three doses of polio vaccine (excluding Oral Polio Vaccine (OPV) given at birth), three doses of pentavalent vaccine and one dose of measles vaccine by 12 months of age. Likewise, we defined a partially immunised child as a child who missed at least any one of the above doses, and an 'un-immunised' or 'zero-dose' child as a child who had not received any vaccine by 12 months of age. ${ }^{36}$ Incomplete immunisation, in this study, includes partially immunised children and unimmunised (zero-dose) children. Immunisation status was based on mothers' recall and immunisation card record (ie, where the mother 
presents an immunisation card, the child's immunisation status is based on records in the card, but where an immunisation card is not available, the immunisation status is based on mothers' recall) as recommended by the WHO. ${ }^{26}$ A number of other studies have used this method, ${ }^{32} 37$ which has proven to be a reliable assessment of immunisation coverage. ${ }^{38-40}$ We did not include vitamin A and yellow fever vaccines in determining complete immunisation status for this study.

\section{Data analysis}

We entered the data into Microsoft Excel (Microsoft, Redmond, Washington, DC, USA), cleaned and transferred to IBM SPSS V.27.0 (IBM, Armonk, New York, USA) for statistical analyses. We used frequency and percentage to describe the data, and $\chi^{2}$ test to test for statistical significance. We used t-test to assess for statistical difference in the mean scores for knowledge of RI. We conducted multivariate logistics regression analyses to estimate adjusted ORs with $95 \%$ CI while adjusting for mothers age, marital status, mothers educational status, mothers occupation, religion, ethnic/tribal group, family monthly income, sex of the index child and source of information on immunisation. We dichotomised aggregate scores for questions on awareness of RI into satisfactory knowledge (10 points and above) and poor knowledge (less than 10 points) prior to inclusion in the regression model. We used $\mathrm{p}<0.05$ to define statistical significance, and all tests were two-tailed.

\section{Patient and public involvement}

No patients nor the public were involved in developing the research question and study design or in the implementation of the study design, the interpretation of the results and writing of the manuscript. There are no plans to share the study with patients, will share with the public through open access publishing.

\section{RESULTS}

\section{Sociodemographic characteristics of mothers and children}

We interviewed 1254 distinct mothers with mean (SD) age of 28.7 (4.3) years. Forty-eight per cent of mothers were aged 20-29 years old, about $89.9 \%$ were married, $93.9 \%$ had at least secondary education or higher and about three-quarters $(75.5 \%)$ were employed. The mean (SD) age of the children was 16.8 (3.3) months, the age ranged from 12 to 23 months and about half (51.0\%) were girls (table 1$)$.

\section{Full immunisation coverage rate}

The full immunisation coverage (FIC) rate in Enugu state was $78.9 \%$ (95\% CI $76.5 \%$ to $81.1 \%$ ), the partially immunised rate was $15.7 \%$ (95\% CI $13.7 \%$ to $17.8 \%$ ), while the unimmunised (zero-dose) rate was 5.4\% (95\% CI $4.2 \%$ to $6.8 \%$ ) (table 2). Vaccination coverage rates for yellow fever vaccine and vitamin A supplement were $86.2 \%$ (95\% CI $84.2 \%$ to $88.1 \%$ ) and $84.4 \%$ (95\% CI $82.3 \%$ to $86.4 \%)$, respectively. DPT3 vaccination coverage
Table 1 Sociodemographic characteristics of mother and children in Enugu state, Nigeria, July 2020

\begin{tabular}{|c|c|c|}
\hline $\begin{array}{l}\text { Sociodemographic } \\
\text { characteristics }\end{array}$ & $\begin{array}{l}\text { Frequency } \\
(\mathrm{N}=1254)\end{array}$ & $\begin{array}{l}\text { Proportion } \\
\text { (\%) }\end{array}$ \\
\hline \multicolumn{3}{|l|}{ Mothers' age } \\
\hline$<20$ years & 54 & 4.3 \\
\hline 20-29 years & 602 & 48.0 \\
\hline$\geq 30$ years & 598 & 47.7 \\
\hline \multicolumn{3}{|l|}{ Marital status } \\
\hline Single & 50 & 4.0 \\
\hline Currently married & 1127 & 89.9 \\
\hline Divorced/widowed & 77 & 7.1 \\
\hline \multicolumn{3}{|l|}{ Mothers' education } \\
\hline Primary or lower & 77 & 6.1 \\
\hline Secondary or higher & 1177 & 93.9 \\
\hline \multicolumn{3}{|l|}{ Mothers' working status } \\
\hline Stay-at-home/housewife & 307 & 24.5 \\
\hline Working mother & 947 & 75.5 \\
\hline \multicolumn{3}{|l|}{ Religion } \\
\hline Christian & 1214 & 96.8 \\
\hline Islam/Muslim & 20 & 1.6 \\
\hline African Traditional Religion & 20 & 1.6 \\
\hline \multicolumn{3}{|l|}{ Family monthly income* } \\
\hline$<\mathrm{N} 40000$ (approx. US\$100) & 544 & 43.4 \\
\hline N40 000-N79 999 & 416 & 33.2 \\
\hline N80 000-N119 999 & 256 & 20.4 \\
\hline$\geq \mathrm{N} 120000$ & 38 & 3.0 \\
\hline \multicolumn{3}{|l|}{ Ethnic group } \\
\hline Igbo & 1201 & 95.8 \\
\hline Others & 53 & 4.2 \\
\hline \multicolumn{3}{|l|}{ Sex/gender of child } \\
\hline Female & 640 & 51.0 \\
\hline Male & 614 & 49.0 \\
\hline \multicolumn{3}{|l|}{ Birth order of child } \\
\hline First born & 347 & 27.7 \\
\hline Second or third & 625 & 49.8 \\
\hline Others & 282 & 22.5 \\
\hline \multicolumn{3}{|l|}{ Residence/community } \\
\hline Rural & 503 & 40.1 \\
\hline Urban & 751 & 59.9 \\
\hline \multicolumn{3}{|c|}{ Walking distance to nearest health facility } \\
\hline$<30$ min walk & 546 & 43.5 \\
\hline$\geq 30$ min walk & 708 & 56.5 \\
\hline
\end{tabular}

Source of information on immunisation (more than source applies)

\begin{tabular}{lll} 
Hospital/health facility & 913 & 72.8 \\
Family/friends & 789 & 62.9 \\
Church/Mosque & 328 & 26.2 \\
\hline
\end{tabular}


Table 1 Continued

\begin{tabular}{lll}
\hline $\begin{array}{l}\text { Sociodemographic } \\
\text { characteristics }\end{array}$ & $\begin{array}{l}\text { Frequency } \\
(\mathbf{N}=\mathbf{1 2 5 4})\end{array}$ & $\begin{array}{l}\text { Proportion } \\
\text { (\%) }\end{array}$ \\
\hline TV, radio and social media & 193 & 15.4
\end{tabular}

*USD=N400.00 on the currency exchange market in July 2020 (www.oanda.com).

rate, which is pentavalent- 3 coverage rate in this study, was $83.9 \%$ (95\% CI $81.7 \%$ to $85.9 \%$ ).

Immunisation coverage rates differed based on the rurality-urbanity of communities in the state. FIC rate was $94.5 \%$ (95\% CI $92.7 \%$ to $96.1 \%$ ) in urban communities and $55.5 \%(95 \%$ CI $51.0 \%$ to $59.9 \%)$ in rural communities. In both urban and rural communities, the proportion of children vaccinated with antigens given at birth and 6 weeks of age were more than the proportions of children vaccinated with antigens given at later ages. Of the 1254 children, 578 possessed immunisation cards, indicating an immunisation card retention rate of $48.7 \%$ (95\% CI $45.9 \%$ to $51.6 \%)$. About two-fifths of unvaccinated (zero-dose) children were not vaccinated because vaccination sites were too far while another two-fifths reported absence of vaccines in the health facility (online supplemental file 1).

\section{Factors associated with immunisation status}

Table 3 shows results from a bivariate analysis of MHC utilisation history and knowledge of RI. Use of SBA during delivery of index child, and reception of postnatal care (at least one postnatal visit) were statistically significant factors associated with incomplete immunisation. Insufficient knowledge of RI was also statistically significantly associated with incomplete immunisation.

Multivariate logistic regression model was statistically significant, $\chi^{2}(25)=24.217, p=0.002$. The model explained $57.0 \%$ (Nagelkerke $\mathrm{R}^{2}$ ) of the variance in immunisation status and correctly classified $90.7 \%$ of cases. Single mothers (aOR=5.74, 95\% CI 1.45 to 22.76), mothers who delivered without SBA (aOR=1.93, 95\% CI 1.24 to 2.99 ), mothers who did not receive any postnatal care $(\mathrm{aOR}=6.53,95 \% \mathrm{CI} 4.17$ to 10.22$)$ and mothers with poor knowledge of RI (aOR=1.76, 95\% CI 1.09 to 2.87) were significant factors associated with incomplete immunisation (table 4). Community level factors associated

Table 2 Immunisation coverage for routine immunisation (RI) antigens in Enugu state, Nigeria, July 2020

\begin{tabular}{|c|c|c|c|}
\hline RI antigen & $\begin{array}{l}\text { State-wide coverage } \\
\mathrm{N}=1254 \\
\mathrm{n}(\%(95 \% \mathrm{Cl}))\end{array}$ & $\begin{array}{l}\text { Coverage in urban communities } \\
\mathrm{N}=751 \\
\mathrm{n}(\%(95 \% \mathrm{Cl}))\end{array}$ & $\begin{array}{l}\text { Coverage in rural communities } \\
\mathrm{N}=503 \\
\mathrm{n}(\%(95 \% \mathrm{Cl}))\end{array}$ \\
\hline \multicolumn{4}{|c|}{ Antigens administered at birth } \\
\hline $\mathrm{BCG}^{*}$ & $1136(90.6(88.8 \%$ to $92.1 \%))$ & $741(98.7(97.6 \%$ to $99.4 \%))$ & $395(78.5(74.7 \%$ to $82.0 \%))$ \\
\hline \multicolumn{4}{|c|}{ Antigens administered at 6 weeks } \\
\hline OPV 1 & $1137(90.7(88.9 \%$ to $92.2 \%))$ & $742(98.8(97.7 \%$ to $99.5 \%))$ & $395(78.5(74.7 \%$ to $82.0 \%))$ \\
\hline \multicolumn{4}{|c|}{ Antigens administered at 10 weeks } \\
\hline OPV 2 & $1083(86.4(84.3 \%$ to $88.2 \%))$ & $741(98.7(97.6 \%$ to $99.4 \%))$ & $342(68.0(63.7 \%$ to $72.1 \%))$ \\
\hline Penta 2 & $1090(86.9(84.9 \%$ to $88.7 \%))$ & $736(98.0(96.7 \%$ to $98.9 \%))$ & $354(70.4(66.2 \%$ to $74.3 \%))$ \\
\hline \multicolumn{4}{|c|}{ Antigens administered at 14 weeks } \\
\hline Measles* & $1101(87.8(85.9 \%$ to $89.6 \%))$ & $716(95.3(93.6 \%$ to $96.7 \%))$ & $385(76.5(72.6 \%$ to $80.2 \%))$ \\
\hline Yellow fever & $1081(86.2(84.2 \%$ to $88.1 \%))$ & $720(95.9(94.2 \%$ to $97.2 \%))$ & $361(71.8(67.6 \%$ to $75.7 \%))$ \\
\hline \multicolumn{4}{|l|}{ Supplements } \\
\hline Vitamin A & $1059(84.4(82.3 \%$ to $86.4 \%))$ & $721(96.0(94.3 \%$ to $97.3 \%))$ & $338(67.2(62.9 \%$ to $71.3 \%))$ \\
\hline \multicolumn{4}{|c|}{ Immunisation status ${ }^{*}$} \\
\hline Fully immunised & $989(78.9(76.5 \%$ to $81.1 \%))$ & $710(94.5(92.7 \%$ to $96.1 \%))$ & $279(55.5(51.0 \%$ to $59.9 \%))$ \\
\hline $\begin{array}{l}\text { Partially } \\
\text { immunised }\end{array}$ & $197(15.7(13.7 \%$ to $17.8 \%))$ & $34(4.5(3.2 \%$ to $6.3 \%))$ & $163(32.4(28.3 \%$ to $36.7 \%))$ \\
\hline $\begin{array}{l}\text { Unimmunised } \\
\text { (zero-dose) }\end{array}$ & $68(5.4(4.2 \%$ to $6.8 \%))$ & $7(0.9(0.4 \%$ to $1.9 \%))$ & $61(12.1(9.4 \%$ to $15.3 \%))$ \\
\hline
\end{tabular}

*Vaccines included in the definition of immunisation status (fully immunised child versus partially immunised versus unimmunised). BCG, bacille Calmette-Guerin; OPV, Oral Polio Vaccine. 
Table 3 Maternal healthcare utilisation history and knowledge of routine immunisation in Enugu state, Nigeria 2020

\begin{tabular}{|c|c|c|c|c|}
\hline Characteristics & $\begin{array}{l}\text { Fully immunised } \\
(\mathrm{n}=989)\end{array}$ & $\begin{array}{l}\text { Not fully immunised } \\
(n=265)\end{array}$ & $\begin{array}{l}\text { Crude } \\
\text { OR }(95 \% \mathrm{Cl})\end{array}$ & $P$ value \\
\hline \multicolumn{5}{|l|}{ Mothers' healthcare utilisation history } \\
\hline \multicolumn{5}{|l|}{ Use of skilled birth attendants (SBA) } \\
\hline Yes (hospital) & $309(84.7 \%)$ & $56(15.3 \%)$ & 1.70 (1.23 to 2.35$)$ & 0.001 \\
\hline No (TBA, home delivery) & $680(76.5 \%)$ & $209(23.5 \%)$ & & \\
\hline \multicolumn{5}{|l|}{ Attended ante-natal care } \\
\hline$\geq$ Four ante-natal visits & $762(77.8 \%)$ & $217(22.2 \%)$ & $0.74(0.53$ to 1.05$)$ & 0.091 \\
\hline$<$ Four ante-natal visits & $227(82.5 \%)$ & $48(17.5 \%)$ & & \\
\hline \multicolumn{5}{|l|}{ Tetanus toxoid (TT) injection during pregnancy } \\
\hline$\geq 2 T \mathrm{~T}$ injections & $784(79.0 \%)$ & $209(21.0 \%)$ & $1.03(0.74$ to 1.43$)$ & 0.888 \\
\hline$<2 \mathrm{TT}$ injection & $205(78.5 \%)$ & $56(21.5 \%)$ & & \\
\hline \multicolumn{5}{|l|}{ Attended post-natal care } \\
\hline Yes & $866(89.2 \%)$ & $105(10.8 \%)$ & 10.73 (7.87 to 14.63$)$ & $<0.001$ \\
\hline No & $123(43.5 \%)$ & $160(56.5 \%)$ & & \\
\hline \multicolumn{5}{|l|}{ Mothers' awareness of routine immunisation } \\
\hline \multicolumn{5}{|l|}{ What do vaccines do to your child's body? } \\
\hline Vaccines help prevent illness & $937(78.5 \%)$ & $256(21.5 \%)$ & 0.63 (0.31 to 1.30$)$ & 0.210 \\
\hline Other responses* & $44(88.0 \%)$ & $6(12.0 \%)$ & & \\
\hline I do not know* & $8(72.7 \%)$ & $3(27.3 \%)$ & & \\
\hline \multicolumn{5}{|c|}{ Mention any disease(s) children's vaccines can prevent } \\
\hline Mentioned four (4) or more diseases & $481(90.6 \%)$ & $50(9.4 \%)$ & 4.07 (2.92 to 5.68$)$ & $<0.001$ \\
\hline Less than four (4) diseases* & $502(70.1 \%)$ & $214(29.9 \%)$ & & \\
\hline I do not know* & $6(85.7 \%)$ & $1(14.3 \%)$ & & \\
\hline \multicolumn{5}{|l|}{ At what age does child immunisation start? } \\
\hline Just after birth & $858(84.6 \%)$ & $156(15.4 \%)$ & 4.58 (3.37 to 6.22$)$ & $<0.001$ \\
\hline Stated other dates ( 1 week, 1 month, etc) ${ }^{*}$ & $95(50.3 \%)$ & $94(49.7 \%)$ & & \\
\hline I do not know* & $36(70.6 \%)$ & $15(29.4 \%)$ & & \\
\hline \multicolumn{5}{|l|}{ When does a child complete his/her immunisation? } \\
\hline $9-15$ months & $930(79.6 \%)$ & $238(20.4 \%)$ & 1.79 (1.11 to 2.88$)$ & 0.016 \\
\hline$<6$ months or $>15$ months $^{\star}$ & $51(67.1 \%)$ & $25(32.9 \%)$ & & \\
\hline I do not know* & $8(80.0 \%)$ & $2(20.0 \%)$ & & \\
\hline \multicolumn{5}{|l|}{ What is the age/schedule for each vaccine? } \\
\hline Correct schedule for three or more vaccines & $952(83.3 \%)$ & $191(16.7 \%)$ & 9.97 (6.52 to 15.24$)$ & $<0.001$ \\
\hline Other responses* & $26(26.3 \%)$ & $73(73.7 \%)$ & & \\
\hline I do not know* & $11(91.7 \%)$ & $1(8.3 \%)$ & & \\
\hline \multicolumn{5}{|c|}{ How many HF visits are required for full immunisation? } \\
\hline At least 5 or 6 visits & $686(80.4 \%)$ & $167(19.6 \%)$ & $1.33(1.00$ to 1.76$)$ & 0.049 \\
\hline$<5$ visits $^{*}$ & $183(88.0 \%)$ & $25(12.0 \%)$ & & \\
\hline I do not know* & $120(62.2 \%)$ & $73(37.8 \%)$ & & \\
\hline \multicolumn{5}{|l|}{ Scores for knowledge of routine immunisation } \\
\hline Mean score $( \pm S D)$ & $10.71(1.61)$ & $9.63(1.82)$ & $1.07(0.83$ to 1.32$) \dagger$ & $<0.001$ \\
\hline
\end{tabular}

*These responses were combined for estimation of crude OR.

†Mean difference (95\% Cl).

HF, health facility; TBA, Traditional birth attendant. 
Table 4 Factors associated with immunisation status of children aged 12-23 months in Enugu state, Nigeria, July 2020

\begin{tabular}{|c|c|c|c|c|}
\hline Sociodemographic characteristics & Reference & Adjusted OR & $95 \% \mathrm{Cl}$ & $P$ value \\
\hline \multicolumn{5}{|l|}{ Individual level factors } \\
\hline \multicolumn{5}{|l|}{ Mothers' age } \\
\hline$<20$ years & 20-29 years & 0.17 & 0.03 to 1.06 & 0.058 \\
\hline$\geq 30$ years & $20-29$ years & 0.87 & 0.57 to 1.34 & 0.534 \\
\hline \multicolumn{5}{|l|}{ Marital status } \\
\hline Single & Married & 5.74 & 1.45 to 22.76 & 0.013 \\
\hline Divorced/widowed & Married & 1.35 & 0.60 to 3.07 & 0.468 \\
\hline \multicolumn{5}{|l|}{ Mothers' educational status } \\
\hline Primary education or lower & Secondary education or higher & 0.64 & 0.26 to 1.56 & 0.383 \\
\hline \multicolumn{5}{|l|}{ Mother's working status } \\
\hline Working mother & Stay-at-home/housewife & 1.08 & 0.63 to 1.85 & 0.327 \\
\hline \multicolumn{5}{|l|}{ Religion of family } \\
\hline Islam/Muslim & Christian & 1.53 & 0.27 to 8.62 & 0.627 \\
\hline African traditional & Christian & 2.21 & 0.44 to 11.13 & 0.335 \\
\hline \multicolumn{5}{|l|}{ Sex of the child } \\
\hline Male & Female & 0.98 & 0.66 to 1.45 & 0.914 \\
\hline \multicolumn{5}{|l|}{ Child's birth order } \\
\hline Second/third child & First child & 1.52 & 0.78 to 2.98 & 0.220 \\
\hline Fourth and later children & First child & 1.34 & 0.48 to 3.74 & 0.577 \\
\hline
\end{tabular}

Maternal healthcare utilisation

Antenatal care (ANC)

$<4$ ANC visits

$\geq 4$ ANC visits

1.52

0.71 to 3.22

0.472

Maternal tetanus toxoid

$<2$ doses

$\geq 2$ doses

0.93

0.41 to 2.10

0.864

Use of skilled birth attendants

No

Yes

1.93

1.24 to 2.99

0.003

Postnatal care

No

Yes

6.53

4.17 to $10.22<0.001$

Knowledge of routine immunisation

Mothers' knowledge of RI

$\begin{array}{lllll}\text { Poor } & \text { Satisfactory } & 1.76 & 1.09 \text { to } 2.87 & 0.022\end{array}$

Community level factors

Area of residence

Rural

Urban

7.49

4.84 to 11.59

$<0.001$

Household monthly income

$<$ N80 000 (approx. US\$200)

$\geq \mathrm{N} 80000$ (approx. US\$200)

1.56

1.17 to 2.81

$<0.001$

Distance to nearest vaccination point $\geq 30$ min walk

$<30$ min walk

2.15

1.31 to 3.52

0.003

$\mathrm{Rl}$, routine immunisation.

with incomplete immunisation were rural community (aOR=7.49, 95\% CI 4.84 to 11.59), low-income households ( $\mathrm{aOR}=1.56,95 \% \mathrm{CI} 1.17$ to 2.81 ), and living further than $30 \mathrm{~min}$ walking distance from the nearest vaccination facility ( $\mathrm{aOR}=2.15$, 95\% CI 1.31 to 3.52$)$.

\section{DISCUSSION}

This study evaluated immunisation coverage data in urban and rural areas of Enugu state and offers a close-up assessment of sociodemographic factors associated with incomplete immunisation at the subnational and local 
level. There are four main findings from this study. First, this assessment of immunisation coverage of children aged 12-23 months in 50 randomly selected wards in rural and urban districts (LGA) in Enugu state found FIC rate in Enugu state to be low, below the Reaching Every District (RED's) subnational target of $80 \%$ immunisation coverage. About one in five $(21.1 \%)$ children aged 12-23 months in the state were not fully immunised. This suggests that even after almost two decades of implementing the RED strategy in Nigeria, some states in the southern region with purportedly high immunisation coverage $^{14}$ did not yet meet the (RED's) subnational immunisation target. This partially explains why huge investments in immunisation activities have had minimal impact on the incidence of vaccine preventable diseases in Enugu state. ${ }^{41}$

The FIC rate in this study is higher than FIC rates reported in other subregions in Nigeria, ${ }^{33} 41$ and Ethiopia, ${ }^{4243}$ and lower than FIC rates reported in Cameroon ${ }^{37}$ and Ghana. ${ }^{44}$ The FIC rate is also substantially higher than the FIC rate reported for Enugu state (36.4\%) in the latest (2018) Nigeria DHS. ${ }^{25}$ There are three possible reasons for this difference. The first reason relates to the definition of FIC: FIC was defined for DHS as having received one dose of BCG, one dose of measles, three doses of DPT and three doses of OPV vaccines (p224) ${ }^{25}$ FIC for this study was likewise defined as in DHS, but for OPV, we defined as three doses of polio vaccine instead, that is either three doses of OPV or two doses of OPV and one dose of Inactivated polio vaccine (IPV) ${ }^{42}$ in line with the Polio Endgame Strategy 2019-2023. ${ }^{43}$ To illustrate how the difference in FIC definition drives the overall rates, we calculated FIC by applying our definition to the DHS data which shows that FIC rates in the current study and DHS are within 11 percentage points when our definition of FIC is used (online supplemental file 2). Additionally, difference in the sampling approaches used in our study and DHS, and the resulting differences in the characteristics of the sample could explain some of the difference. A comparison of demographic characteristics of our sample with that of the DHS sample (in Enugu state) shows that mothers in our sample are more educated and more likely to be working (online supplemental file 3 ). It is reasonable to expect a higher FIC among these mothers. ${ }^{10} 34$ Strikingly, children in our sample are of lower birth order than in the DHS and disproportionately from rural area. It appears that higher vaccination rates among younger more educated and working mothers is less than offset by lower vaccination rate among children of lower birth order and those from rural areas. Finally, a portion of the difference could be due to the State Government's recent efforts to boost vaccination coverage in the state since the 2018 Nigeria DHS. ${ }^{24}$

Second, further analysis based on rurality of residence reveals stark disparity in the FIC rate between urban communities and rural communities. Urban communities had a substantially higher FIC rate $(94.5 \%)$ than rural communities $(55.5 \%)$. This observation is consistent with findings in other subregions in Nigeria, ${ }^{44} 45$ and Ethiopia, ${ }^{4647}$ but differs with findings in Bayelsa State, Nigeria where immunisation coverage was higher in the rural community than in the urban community. ${ }^{48}$ Our data show that almost half of infants in rural communities miss out on at least one of the critical life-saving BCG, Pentavalent, Polio and Measles vaccines. This finding underscores the importance of monitoring data at subdistrict levels to identify vaccination gaps and tailor operational strategies accordingly.

Third, the low DPT-3 coverage in rural communities $(63.0 \%)$ points to gaps in RI delivery in those communities and is consistent with a study conducted in another rural community in Enugu. ${ }^{49}$ Furthermore, the immunisation dropout rate in both urban and rural communities is low, below the $10 \%$ cut-off recommended by WHO.$^{50}$ The low immunisation dropout rate $(<10.0 \%)$ and the low DPT-1 coverage in rural communities $(78.5 \%)$ together suggests that access to RI services in these contexts remains a problem, ${ }^{50}$ as a previous study have suggested. ${ }^{49}$ There are many factors responsible for the rural-urban differences in access. For example, vaccination points are more geographically accessible to families in urban communities than in rural communities, ${ }^{10} 5152$ rural communities incur higher travel costs to reach vaccination points ${ }^{52}$ and rural communities are less aware of the importance of immunisation. ${ }^{1044}$

Finally, marital status, MHC utilisation, poor knowledge of RI, poor family income and geographical accessibility were associated with incomplete immunisation at the district level. Children of single mothers are less likely to be fully immunised compared with married mothers. Married mothers are more financially stable and most likely to discuss the health needs of their children, including immunisation. ${ }^{51}{ }^{53}$ Also, stigma, psychological trauma and hardship associated with single motherhood in these contexts negatively impacts access to health and vaccination. ${ }^{5153}$ MHC utilisation also significantly predicts incomplete immunisation. Mothers who give birth using SBA are more likely to have them fully immunised than mothers who did not use SBA. Likewise, mothers who receive $\mathrm{PNC}$ care are more likely to have their children fully immunised. This is consistent with several studies in other low-income and middle-income countries (LMICs) that demonstrate that increased health communications on immunisation during MHC utilisation was significantly associated with childhood immunisation. ${ }^{51} 54$ However, given that the sequence of MHC utilisation is ANCSBA-PNC, the absence of a significant effect for ANC in this study does not imply that adequate ANC attendance is not associated with RI. Instead, our data suggest that other factors such as accessibility to health facilities could have a stronger association with RI than adequately attending ANC. ${ }^{55}$

\section{Strengths and limitations}

Our study extends the body of knowledge on immunisation uptake in rural areas vis-à-vis urban areas at the 
subnational level, our results can be generalised to similar contexts in Nigeria and beyond and provides important evidence to policymakers and programme managers for improving immunisation coverage. However, our study is not without limitations. First, health system factors including vaccine availability, healthcare personnel and logistics, ${ }^{56} 57$ which are known to influence uptake of immunisation coverage were not adequately explored. Also, paternal factors that may influence the completion of immunisation were not evaluated. ${ }^{51}$ However, the primary goal of this study was not to assess the effect of these factors. Second, new vaccines recently introduced into the Nigeria RI schedule (specifically, Rotavirus vaccine and Pneumococcal conjugate vaccine) were not explored. ${ }^{58} 59$ Third, although maternal recall has been shown to be a reliable estimate of maternal recall in Senegal, Ethiopia and Tanzania, ${ }^{38-40}$ there is little evidence that it is a reliable coverage measure in Nigeria. A similar study in Osun state showed that agreement between the mothers' recall and immunisation card assessment was low. ${ }^{33}$ This (maternal recall) could have also biased our estimates. Finally, pockets of hard-to-reach Fulani settlements that have been shown to have poor immunisation coverage were not included in our sample. ${ }^{60}$ Due to the deteriorating security situation in the country and the absence of security assurances, we could not send data collectors to these settlements.

\section{Policy implications}

Our study findings have policy implications for vaccination delivery in LMICs attempting to improve national and subnational immunisation coverage. Innovative solutions to improve geographical accessibility are undoubtedly needed to achieve IA2030 targets at local levels. Also, our study found that mothers who used MHC services were significantly more likely to have full immunised children suggesting that improving MHC utilisation, especially in underserved rural communities, might be an effective strategy in achieving the IA2030 national and subnational targets. ${ }^{54}$ However, further studies, preferably randomised controlled trials, are needed to confirm if strategies aimed at improving MHC utilisation actually improve immunisation rate. Finally, our study demonstrates the importance of reporting vaccination coverage at the local/district level to draw attention to regional inequities at that level and identify regions/districts for more targeted interventions.

\section{CONCLUSIONS}

The FIC rate in rural communities in Enugu state is below the RED target of $80 \%$ for all antigens by 2020 . About one in two children in rural communities in Enugu state is not fully immunised. Sociodemographic factors associated with full immunisation at the subnational level are single motherhood, MHC utilisation, family income, rural residence and geographical proximity to health facilities.

\section{Twitter Sergius Alex Agu @agusergiusalex}

Acknowledgements The authors are immensely grateful to Mrs Priscilla Aniekwe and George Okafor for invaluable assistance with the data collection. We are also indebted to our team of community social workers without whom this study would not have been possible.

Contributors PE and YA conceptualised the study, oversaw its conduct, analysed the data, interpreted the results, drafted the original article and reviewed the final draft. UJA, CLA, SAA and LOL contributed to the collection and analysis of the data, interpretation of the results and review of the final draft. All authors read and approved the final manuscript.

Funding The authors have not declared a specific grant for this research from any funding agency in the public, commercial or not-for-profit sectors.

Map disclaimer The depiction of boundaries on the map(s) in this article does not imply the expression of any opinion whatsoever on the part of $B M J$ (or any member of its group) concerning the legal status of any country, territory, jurisdiction or area or of its authorities. The map(s) are provided without any warranty of any kind, either express or implied.

Competing interests None declared.

Patient consent for publication Not required.

Ethics approval Ethical approval for the study was obtained from the Ethical Committee of the Enugu State University Teaching Hospital-Reference number: ESUTHP/C-MAC/RA/034/Nol1/264. Permission was also obtained from the State Ministry of Health, Enugu. Informed verbal consent was obtained from each mother before participating in the study. Verbal consent was deemed appropriate and approved by the ethics committee. Informed verbal consent consisted of a description of the objectives of the study, assurance of confidentiality of personal information and a specific request for permission to conduct the interview. Consent was obtained in Igbo (the local language) except for a few non-lgbo speaker whose consent was obtained in English. Where the mother was less than 18 years, consent to participate in the study was obtained from the husband (if mother was married) or from the mother's mother/father (if the mother was single). Children with zero or incomplete immunisation were referred to the nearest health centre for vaccination. All patient identifiers were removed prior to statistical analysis.

Provenance and peer review Not commissioned; externally peer reviewed.

Data availability statement Data are available in a public, open access repository. The dataset generated and analysed in this study is freely available from the corresponding author on reasonable request or directly from the data repository, Zenodo (http://doi.org/10.5281/zenodo.4294847).

Supplemental material This content has been supplied by the author(s). It has not been vetted by BMJ Publishing Group Limited (BMJ) and may not have been peer-reviewed. Any opinions or recommendations discussed are solely those of the author(s) and are not endorsed by BMJ. BMJ disclaims all liability and responsibility arising from any reliance placed on the content. Where the content includes any translated material, BMJ does not warrant the accuracy and reliability of the translations (including but not limited to local regulations, clinical guidelines, terminology, drug names and drug dosages), and is not responsible for any error and/or omissions arising from translation and adaptation or otherwise.

Open access This is an open access article distributed in accordance with the Creative Commons Attribution Non Commercial (CC BY-NC 4.0) license, which permits others to distribute, remix, adapt, build upon this work non-commercially, and license their derivative works on different terms, provided the original work is properly cited, appropriate credit is given, any changes made indicated, and the use is non-commercial. See: http://creativecommons.org/licenses/by-nc/4.0/.

ORCID iD

Paul Eze http://orcid.org/0000-0001-7202-8676

\section{REFERENCES}

1 World Health Organization. Immunization coverage. Fact sheets, 2020. Available: https://www.who.int/news-room/fact-sheets/detail/ immunization-coverage

2 United Nations Children Fund (UNICEF). Immunization. UNICEF data: monitoring the situation of children and women, 2020. Available: https://data.unicef.org/topic/child-health/immunization/

3 Orenstein WA, Ahmed R. Simply put: vaccination saves lives. Proc Natl Acad Sci U S A 2017;114:4031-3. 
4 Rémy V, Zöllner Y, Heckmann U. Vaccination: the cornerstone of an efficient healthcare system. J Mark Access Health Policy 2015;3:27041.

5 Zhou F, Shefer A, Wenger J, et al. Economic evaluation of the routine childhood immunization program in the United States, 2009. Pediatrics 2014;133:577-85.

6 Bärnighausen T, Bloom DE, Canning D, et al. Rethinking the benefits and costs of childhood vaccination: the example of the Haemophilus influenzae type B vaccine. Vaccine 2011;29:2371-80.

7 Armstrong EP. Economic benefits and costs associated with target vaccinations. J Manag Care Pharm 2007;13:12-15.

8 Zhou F, Santoli J, Messonnier ML, et al. Economic evaluation of the 7-vaccine routine childhood immunization schedule in the United States, 2001. Arch Pediatr Adolesc Med 2005;159:1136-44.

9 Greenwood B. The contribution of vaccination to global health: past, present and future. Philos Trans R Soc Lond B Biol Sci 2014;369:20130433-5.

10 Obanewa OA, Newell ML. The role of place of residency in childhood immunisation coverage in Nigeria: analysis of data from three DHS rounds 2003-2013. BMC Public Health 2020;20:1-13.

11 Masresha BG, Dixon MG, Kriss JL, et al. Progress toward measles elimination - African region, 2013-2016. MMWR Morb Mortal Wkly Rep 2017;66:436-43.

12 Masresha B, Braka F, Onwu N, et al. Progress Towards Measles Elimination in Nigeria: 2012 - 2016. J Immunol Sci 2018;2:135-9.

13 Adedokun ST, Uthman OA, Adekanmbi VT, et al. Incomplete childhood immunization in Nigeria: a multilevel analysis of individual and contextual factors. BMC Public Health 2017;17:1-10

14 C. Anyene B. Routine immunization in Nigeria: the role of politics, religion and cultural practices. AJHE 2014;03:01-9.

15 Ophori EA, Tula MY, Azih AV, et al. Current trends of immunization in Nigeria: prospect and challenges. Trop Med Health 2014;42:67-75.

16 Adeloye D, Jacobs W, Amuta AO, et al. Coverage and determinants of childhood immunization in Nigeria: a systematic review and metaanalysis. Vaccine 2017;35:2871-81.

17 World Health Organization, United Nations Children Fund (UNICEF). Nigeria - WHO and UNICEF estimates of immunization coverage, 2019 revision. WHO UNICEF Immunization Coverage Estimates. p. 1-33, 2020. Available: https://www.who.int/immunization/monitoring surveillance/data/nga.pdf

18 Mosser JF, Gagne-Maynard W, Rao PC, et al. Mapping diphtheriapertussis-tetanus vaccine coverage in Africa, 2000-2016: a spatial and temporal modelling study. The Lancet 2019;393:1843-55.

19 Gunnala R, Ogbuanu IU, Adegoke OJ, et al. Routine vaccination coverage in northern Nigeria: results from 40 district-level cluster surveys, 2014-2015. PLoS One 2016;11:e0167835-5.

20 World Health Organization (WHO). Immunization agenda 2030: a global strategy to leave no one behind, 2019. Available: https://www. who.int/publications/m/item/immunization-agenda-2030-a-globalstrategy-to-leave-no-one-behind

21 World Health Organization. The red strategy. immunization, vaccines and biologicals, 2018. Available: https://www.who.int/immunization/ programmes systems/service_delivery/red/en/

22 Corsi DJ, Neuman M, Finlay JE, et al. Demographic and health surveys: a profile. Int J Epidemiol 2012;41:1602-13.

23 Dunkle SE, Wallace AS, MacNeil A, et al. Limitations of using administratively reported immunization data for monitoring routine immunization system performance in Nigeria. $J$ Infect Dis 2014;210 Suppl 1:S523-30.

24 World Health Organization. Enugu State inaugurates Task Force on Immunization, to close gaps in immunization coverage [Internet]. WHO Africa / Nigeria. 2020 [cited 2020 Apr 20]. Available from. Available: https://www.afro.who.int/news/enugu-state-inauguratestask-force-immunization-close-gaps-immunization-coverage

25 National Population Commission (NPC) Nigeria, ICF. Nigeria Demographic Health Survey 2018 [Internet]. Abuja, Nigeria and Rockville, Maryland, USA; 2019. Available from. Available: https:// dhsprogram.com/publications/publication-fr359-dhs-final-reports. cfm

26 World Health Organization. World Health Organization Vaccination Coverage Cluster Surveys: Reference Manual [Internet]. Geneva: World Health Organization; 2018. 234 p. Available from. Available: https://www.who.int/immunization/documents/who_ivb_18.09/en/

27 von Elm E, Altman DG, Egger M, et al. The strengthening the reporting of observational studies in epidemiology (STROBE) statement: guidelines for reporting observational studies. Epidemiology 2007;18:800-4.

28 Ekoh PC, George E, Ejimkaraonye C. Nigeria demographic report: the effect of overpopulation on life expectancy. African Popul Stud 2020;34:5106-14.
29 National Population Commission, National Bureau of Statistics. National, state and local government population forecasts. Abuja, Nigeria: National Population Commission, 2016.

30 Eze P, Agu UJ, Aniebo CL, et al. Perception and attitudinal factors contributing to periodic deworming of preschool children in an urban slum, Nigeria. BMC Public Health 2020;20:1-12.

31 Odusanya OO, Alufohai EF, Meurice FP, et al. Determinants of vaccination coverage in rural Nigeria. BMC Public Health 2008;8:1-8.

32 Uzochukwu BS, Okeke CC, Envuladu E, et al. Inequity in access to childhood immunization in Enugu urban, Southeast Nigeria. Niger $J$ Clin Pract 2017;20:971-7.

33 Adedire EB, Ajayi I, Fawole Ol, et al. Immunisation coverage and its determinants among children aged 12-23 months in Atakumosa-west district, Osun state Nigeria: a cross-sectional study. BMC Public Health 2016;16:1-8.

34 Gidado S, Nguku P, Biya O, et al. Determinants of routine immunization coverage in Bungudu, Zamfara state, Northern Nigeria, may 2010. Pan Afr Med J 2014;18:1-5.

35 National Primary Healthcare Development Agency (NPHCDA). National immunization schedule in Nigeria. Publications, 2018. Available: https://nphcda.gov.ng/publications/

36 World Health Organization. Fully immunized child rate. the global health Observatory, 2020. Available: https://www.who.int/data/gho/ indicator-metadata-registry/imr-details/3376

37 Russo G, Miglietta A, Pezzotti P, et al. Vaccine coverage and determinants of incomplete vaccination in children aged 12-23 months in Dschang, West region, Cameroon: a cross-sectional survey during a polio outbreak. BMC Public Health 2015;15:1-11.

38 Seror V, Cortaredona S, Ly EY, et al. Vaccination card availability and childhood immunization in Senegal. BMC Public Health 2020;20:1-13.

39 Porth JM, Wagner AL, Tefera YA, et al. Childhood immunization in Ethiopia: accuracy of maternal recall compared to vaccination cards. Vaccines 2019;7:48-12.

40 Binyaruka P, Borghi J. Validity of parental recalls to estimate vaccination coverage: evidence from Tanzania. BMC Health Serv Res 2018;18:1-9.

41 Chukwuemeka EEO, Aduma A, Ezeigwe FO. A Re-Interrogation of immunization programme in Enugu state Nigeria: impediments and way forward. JPMR 2019;5:45-61.

42 Polio Global Eradication Initiative and Expanded Programme on Immunization (EPI). Polio and the introduction of IPV, 2014. Available: https://www.who.int/immunization/diseases/poliomyelitis/ inactivated polio vaccine/Key_mess_FAQs.pdf

43 World Health Organization (WHO). Polio endgame strategy 20192023: eradication, integration, certification and containment. World Heal Organ 2019;64.

44 Olugbenga-Bello A, Jimoh A, Oke O. Maternal characteristics and immunization status of children in North central of Nigeria. Pan Afr Med J 2017;26:1-15

45 Brown VB, Oluwatosin OA. Socio-Demographic factors associated with childhood immunization uptake in Akinyele local government area, Oyo state, Nigeria. Afr J Med Med Sci 2012;41:161-7.

46 Kassahun MB, Biks GA, Teferra AS. Level of immunization coverage and associated factors among children aged 12-23 months in Lay Armachiho District, North Gondar Zone, Northwest Ethiopia: a community based cross sectional study. BMC Res Notes 2015;8:1-10.

47 Mohamud AN, Feleke A, Worku W, et al. Immunization coverage of 12-23 months old children and associated factors in Jigjiga District, Somali National Regional State, Ethiopia. BMC Public Health 2014;14:1-9.

48 Itimi K, Dienye PO, Ordinioha B. Community participation and childhood immunization coverage: a comparative study of rural and urban communities of Bayelsa state, South-South Nigeria. Niger Med J 2012;53:21-5.

49 Chinawa JM. Immunization dropout rates in Ihe, Awgu local government area, Enugu state, South East Nigeria: a 1 year review. Ann Med Health Sci Res 2014;4:642-6.

50 World Health Organization/United Nations Children's Fund. Increasing immunization coverage at the health facility level [Internet]. Vaccines and Biologicals, 2002. Available: https://apps. who.int/iris/bitstream/handle/10665/67791/WHO V\&B 02.27.pdf? sequence $=1$

51 Bangura JB, Xiao S, Qiu D, et al. Barriers to childhood immunization in sub-Saharan Africa: a systematic review. BMC Public Health 2020;20:1108.

52 Sibeudu FT, Uzochukwu BSC, Onwujekwe OE. Rural-urban comparison of routine immunization utilization and its determinants in communities in Anambra states, Nigeria. SAGE Open Medicine 2019;7:205031211882389. 
53 Baguune B, Ndago JA, Adokiya MN. Immunization dropout rate and data quality among children 12-23 months of age in Ghana. Arch Public Health 2017;75:1-8.

54 Anichukwu OI, Asamoah BO. The impact of maternal health care utilisation on routine immunisation coverage of children in Nigeria: a cross-sectional study. BMJ Open 2019;9:e026324-11.

55 Huldah ljeoma N. Use of telephone calls in reduction of dropout rate of routine immunization in a tertiary health facility in South Eastern Nigeria. EJPM 2015;3:39.

56 Gooding E, Spiliotopoulou E, Yadav P. Impact of vaccine stockouts on immunization coverage in Nigeria. Vaccine 2019;37:5104-10.

57 Burnett RJ, Mmoledi G, Ngcobo NJ, et al. Impact of vaccine stockouts on infant vaccination coverage: a hospital-based survey from South Africa. Int Health 2018;10:376-81.

58 World Health Organization. Nigeria to AVERT over 160,000 deaths in children yearly, with introduction of rotavirus vaccine into immunization schedule. who Africa/Nigeria, 2018. Available: https:// www.afro.who.int/news/nigeria-avert-over-160000-deaths-childrenyearly-introduction-rotavirus-vaccine-immunization

59 World Health Organization. Nigeria introduces new vaccine - PCV 10. who Africa/Nigeria, 2014. Available: https://www.afro.who.int/news/ nigeria-introduces-new-vaccine-pcv-10\#: :text=On 22nd December 2014 the,caused by the pneumococcal bacteria

60 Okeibunor JC, Onyeneho NG, Nwaorgu OC, et al. Prospects of using community directed intervention strategy in delivering health services among Fulani nomads in Enugu state, Nigeria. Int $J$ Equity Health 2013;12:24-17.

61 Ugoyibo OV, Amaechi IF, Obinna AC. Evaluation of groundwater pollution sources in Enugu North LGA of Enugu state, Nigeria. IJSAR J Environ Earth Phys Sci 2015;2:54-69. 